\title{
Effects of velocity on upper to lower extremity muscular work and power output ratios of intercollegiate athletes
}

\author{
Jack Charteris
}

\begin{abstract}
Objectives-Peak torque expresses a point output which may, but does not always, correlate well with full range output measures such as work or power, particularly in a rehabilitating muscle. This study evaluates isokinetic performance variables, particularly $(a)$ flexor to extensor work and power output ratios of upper and lower extremities and $(b)$ overall upper to lower extremity work and power ratios, in intercollegiate athletes. The purpose was to ascertain how speeds of 30 and 180 degrees/s influence agonist to antagonist ratios for torque, work, and power and to determine the effects of these speeds on upper to lower limb flexor (F), extensor $(E)$, and combined $(F+E)$ ratios, as a guide to rehabilitation protocols and outcomes after injury.
\end{abstract}

Methods-Twenty seven athletic men without upper or lower extremity clinical histories were tested isokinetically at slow and moderately fast speeds likely to be encountered in early stages of rehabilitation after injury. Seated knee extensor and flexor outputs, particularly work and power, were investigated, as were full range elbow extensor and flexor outputs. The subjects were morphologically similar in linearity and muscularity (coefficient of variation $4.17 \%$ ) so that standardisation of isokinetic outputs to body mass effectively normalised for strength differences due to body size. Peak torque $(\mathrm{N} . \mathrm{m} / \mathrm{kg})$, total work $(\mathrm{J} / \mathrm{kg}$ ), and average power (W/kg) for elbow and knee flexions and extensions were measured on a Cybex 6000 isokinetic dynamometer. With respect to the raw data, the four test conditions ( $F$ at 30 degrees/s; $E$ at 30 degrees/s; $F$ at 180 degrees/s; $E$ at 180 degrees/s) were analysed by one way analysis of variance. Reciprocal (agonist to antagonist) $F$ to $E$ ratios of the upper and lower extremities were calculated, as were upper to lower extremity flexor, extensor, and combined $(F+E)$ ratios. Speed related differences between the derived ratios were analysed by Student's $t$ tests (related samples).

Department of Human Kinetics and

Ergonomics, Rhodes University, PO Box 94, Grahamstown 6140, South Africa

J Charteris

Correspondence to: Professor J Charteris.

Accepted for publication 3 February 1999 Results-At the speeds tested all torque responses exhibited velocity related decrements at rates that kept flexor to extensor ratios and upper to lower extremity ratios constant $(p>0.05)$ for work and power. All upper extremity relative torque, work, and power flexion responses were equal to extension responses $(p>0.05)$ regardless of speed. Conversely, all lower extremity relative measures of torque, work, and power of flexors were significantly lower than extensor responses. In the case of both upper and lower extremities, work and power $F$ to $E$ ratios were unaffected by speed. Moreover, increasing speed from 30 to $180 \mathrm{degrees} / \mathrm{s}$ had no effect on upper to lower extremity work and power ratios, whether for flexion, extension, or flexion and extension combined.

Conclusions-Peak torque responses may not adequately reflect tension development through an extensive range of motion. Total work produced and mean power generated, on the other hand, are highly relevant measures of performance, and these, expressed as $F$ to $E$ ratios, are unaffected by speeds of 30 and 180 degrees/s, whether for upper or lower extremities or for upper to lower extremities. In this sample, regardless of speed, the upper extremity produced $55 \%$ of the work and $39 \%$ of the power of the lower extremity, when flexor and extensor outputs were combined. Injured athletes are, in the early stages of function restoration, often not able to exert tension at fast speeds. An understanding of upper to lower extremity muscular work and power ratios has important implications for muscle strengthening after injury. Knowledge of normal upper to lower extremity work and power output ratios at slow to moderately fast isokinetic speeds is particularly useful in cases of bilateral upper (or lower) extremity rehabilitation, when the performance of a contralateral limb cannot be used as a yardstick. (Br f Sports Med 1999;33:250-254)

Keywords: performance testing; muscular activity; isokinetics; rehabilitation; musculoskeletal injury

The study of decrements in peak force with increases in speed of motion has a long tradition. The force-velocity relation has been shown in vitro ${ }^{12}$ and in vivo. ${ }^{3-7}$ Likewise the weakness of the upper extremity relative to the lower, especially in terms of peak torque outputs, is well established. ${ }^{8-10}$

In the speed range 30-120 degrees/s, some ment of $11.8 \%,{ }^{6}$ while others, in comparable lower limb studies, have shown a speed related decrement of $14.1 \%,{ }^{11}$ prompting the suggestion that upper limb torque and work outputs may decrease at a lower rate than occurs in the 
lower limb as speed of performance increases. Obviously both flexors (F) and extensors (E) will show overall torque (and hence work output) decrements with increases in speed, ${ }^{12} 13$ but unless these decrease at the same rate, the $\mathrm{F}$ to $\mathrm{E}$ ratios will either increase or decrease, depending upon their relative rates of decrement as speeds increase. It has also been shown $^{14}$ that between 60 and 300 degrees/s, upper extremity flexors and extensors decrease at similar rates, so that $\mathrm{F}$ to $\mathrm{E}$ ratios remain effectively at 1.0 regardless of speed. Unfortunately only peak torques, not total work or average power outputs, were investigated.

In isokinetic tests, measures of peak torque, although useful, represent performance at some (usually unspecified) point in the range of motion. A higher peak torque in one subject is no guarantee of greater total work output or of greater average power generation than in another. The clearly superior measure of full range tension development is that of "summated torques"- that is area under the torque curve, representing work produced. Yet studies of speed effects ${ }^{5}$ and upper to lower extremity performance ratios ${ }^{9}$ have tended to concentrate on peak torque effects rather than total work or average power output. ${ }^{15}$

In isokinetic dynamometry, if torque decrements are outpaced by speed related reductions in available performance time then, although torque and work outputs decrease, power outputs will increase with increased speed of motion. For instance, knee excursions through $90^{\circ}$ take three seconds at 30 degrees/s test speed and 0.5 seconds at 180 degrees/s test speed. If, in this situation, there is a $32 \%$ reduction in work production, associated with an $83 \%$ reduction in time to produce it, there will obviously be a predictable rise in power output.

From the foregoing it is clear as a generalisation that peak torque decreases as speed increases. It is also clear that the $\mathrm{F}$ to $\mathrm{E}$ ratio of the upper extremity is effectively 1.0 regardless of speed, while the $\mathrm{F}$ to $\mathrm{E}$ ratio of the lower extremity increases as speed increases. Some researchers, ${ }^{16}$ for example, found knee $\mathrm{F}$ to $\mathrm{E}$ ratios of 0.62 at 30 degrees/s and 0.88 at 300 degrees/s for peak torque. However, peak torque is not invariably a good indicator ${ }^{7}$ of full range functional capacity (see below), and the literature is in any case not clear whether what holds for peak torque also holds for total work production through the full range of motion and for average power output. Moreover, it is not clear in the literature whether speed increments in the range from 30 to 180 degrees/s are sufficient to show torque-velocity effects to the point where $F$ to $E$ ratios and upper to lower extremity ratios may be affected.

The purpose of this study was to evaluate flexor to extensor ratios of both upper and lower

Table 1 Basic demographic data

\begin{tabular}{lllll}
\hline & Age (years) & Stature $(\mathrm{mm})$ & Mass $(\mathrm{kg})$ & $R P I\left(\mathrm{~mm}^{3} \mathrm{~kg}\right)$ \\
\hline Mean & 21 & 1830 & 84 & 419.4 \\
Standard deviation & 2 & 50 & 13 & 17.5 \\
Range & $19-24$ & $1670-1980$ & $57-108$ & $386.9-454.7$ \\
\hline
\end{tabular}

RPI, reciprocal ponderal index (stature $\sqrt[3]{\text { mass) }}$. extremities under a sixfold speed increment from 30 to 180 degrees/s and to determine whether upper to lower extremity ratios for work and power remain constant as speed increases. Isokinetic speeds under 60 degrees/s have been described as "low" and speeds between 60 and 180 degrees/s as "intermediate" ${ }^{17}$. Such attributions are value judgments about which researchers may disagree. However, these speeds are well within the slowest third of the test speed range (0-500 degrees/s) of the Cybex 6000 dynamometer used in this study and are regarded as "slow" (30 degrees/s) and "moderately fast" (180 degrees/s). In any case even the fastest test speed available in isokinetic dynamometry is well below in vivo limb angular velocities. For example, knee velocities around 900 degrees/s have been found in runners, ${ }^{18}$ and angular velocities of over 4500 degrees/s have been recorded in elbow excursions during throwing actions..$^{19}$ In relation to in vivo demands, the test speeds used here are indeed slow. In the early stages of reconditioning after musculoskeletal trauma, subjects may not be able to move at high speed; it may therefore be necessary to monitor strength gains at slower speeds. This study therefore sought to determine whether well motivated athletes would show the same rate of upper to lower extremity ratio decrements, which the literature suggests are likely to be evidenced in the 30-300 degrees/s speed range.

\section{Materials and methods}

Twenty seven physically active young adult men, all without upper or lower extremity musculoskeletal clinical histories, voluntarily participated in this study, which was conducted in accordance with institutional research ethics guidelines. All subjects were right dominant competitive intercollegiate level athletes in diverse sports, and the right elbow and knee flexors and extensors were tested isokinetically at 30 and 180 degrees/s machine speeds. Knee flexion-extension tests were conducted in the seated position and elbow flexion-extension tests in the supine position, as these test positions are the most frequently reported in the literature and conform to the manufacturer's recommendations. As the aim was to provide practical clinical guidelines for rehabilitation, it was felt that the data provided should reflect elbow to knee ratios relative to the most frequently used testing positions. The ratios presented here therefore relate specifically to the test positions used.

Extensive pilot testing had failed to show any differences in $\mathrm{F}$ to $\mathrm{E}$ ratios or upper to lower extremity ratios between athletes at this level of performance in sports as diverse as cycling, rowing, road running, and water polo, so the criterion for acceptance of subjects was current membership of an intercollegiate team, regardless of the sport. Table 1 gives the basic demographic data. The subjects were generally lean and muscular, their linearity of physique ${ }^{20}$ being measured by the reciprocal of the ponderal index (see table 1), the coefficient of variation of which $(4.17 \%)$ attests to the fact that the sample did not include subjects of either very ponderous or very gracile physique. 
Table 2 Relative peak torque, best work repetition, and mean power responses (means (SD)) and one way analyses of variance for the four test conditions (flexion (F) at $30^{\circ} / \mathrm{s}$; extension (E) at $30^{\circ} / \mathrm{s}$; flexion at $180^{\circ} / \mathrm{s}$; extension at $180^{\circ} / \mathrm{s}$ )

\begin{tabular}{|c|c|c|c|c|c|c|c|c|c|c|c|}
\hline \multirow[b]{2}{*}{ foints } & \multirow[b]{2}{*}{ Variables } & \multicolumn{4}{|l|}{ Conditions } & \multicolumn{6}{|c|}{ Variance analysis } \\
\hline & & $F 30^{\circ} / \mathrm{s}$ & $E 30^{\circ} / \mathrm{s}$ & $F 180^{\circ} / \mathrm{s}$ & $E 180^{\circ} / \mathrm{s}$ & Source & SS & $D F$ & $M S$ & $F$ & $P$ \\
\hline \multirow[t]{6}{*}{ Elbow } & Peak torque (N.m/kg) & $0.92(0.15)$ & $0.92(0.19)$ & $0.71(0.11)$ & $0.67(0.11)$ & Conditions & 1.4897 & 3 & 0.4966 & 24.364 & 0.0000 \\
\hline & & & & & & Error & 2.1197 & 104 & 0.0204 & & \\
\hline & Best work repetition $(\mathrm{J} / \mathrm{kg})$ & $1.53(0.25)$ & $1.46(0.26)$ & $1.06(0.25)$ & $1.03(0.18)$ & Conditions & 5.5848 & 3 & 1.8616 & 32.855 & 0.0000 \\
\hline & & & & & & Error & 5.8928 & 104 & 0.0567 & & \\
\hline & Mean power output (W/kg) & $0.37(0.06)$ & $0.35(0.06)$ & $1.41(0.26)$ & $1.34(0.30)$ & Conditions & 27.9987 & 3 & 9.3329 & 227.958 & 0.0000 \\
\hline & & & & & & Error & 4.2579 & 104 & 0.0409 & & \\
\hline \multirow[t]{6}{*}{ Knee } & Peak torque $(\mathrm{N} \cdot \mathrm{m} / \mathrm{kg})$ & $1.93(0.28)$ & $3.41(0.46)$ & $1.36(0.20)$ & $2.07(0.28)$ & Conditions & 61.2376 & 3 & 20.4125 & 187.162 & 0.0000 \\
\hline & & & & & & Error & 11.3426 & 104 & 0.1091 & & \\
\hline & Best work repetition $(\mathrm{J} / \mathrm{kg})$ & $2.17(0.42)$ & $3.39(0.57)$ & $1.53(0.28)$ & $2.31(0.36)$ & Conditions & 48.2638 & 3 & 16.0879 & 90.961 & 0.0000 \\
\hline & & & & & & Error & 18.3941 & 104 & 0.1769 & & \\
\hline & Mean power output (W/kg) & $0.75(0.13)$ & $1.16(0.20)$ & $2.74(0.46)$ & $4.29(0.60)$ & Conditions & 211.0000 & 3 & 70.3333 & 449.661 & 0.000 \\
\hline & & & & & & Error & 16.2671 & 104 & 0.1564 & & \\
\hline
\end{tabular}

Significance level: $\mathrm{p}<0.05$

Post-hoc analyses (Tukey) (these results, in each case, hold for all measures (torque, work and power)):

Upper extremity: $\mathrm{F} 30=\mathrm{E} 30$ and $\mathrm{F} 180=\mathrm{E} 180 ; \mathrm{F} 30 \neq \mathrm{F} 180$ and $\mathrm{E} 30 \neq \mathrm{E} 180$

Lower extremity: $\mathrm{F} 30 \neq \mathrm{E} 30$ and $\mathrm{F} 180 \neq \mathrm{E} 180 ; \mathrm{F} 30 \neq \mathrm{F} 180$ and $\mathrm{E} 30 \neq \mathrm{E} 180$

All participants were previously habituated to isokinetic testing requisites and procedures at the experimental speeds reported here. The test device was a Cybex 6000 isokinetic dynamometer (Lumex Inc, Ronkonkoma, New York, USA). Standard manufacturer specified subject positioning guidelines for seated knee and supine elbow flexion-extension testing were followed. Verbal encouragement was given during every trial, care being taken to ensure consistency in this regard.

After an isokinetic warm up involving submaximal efforts in the test position and an ensuing rest period of two to three minutes, each subject performed one set of four maximal effort paired flexion-extension repetitions at each speed. Assignment of speed and extremity tested was random, but each subject completed his experimental contribution within a single test session. A 60 second rest was provided between sets. Strength measures of torque, work, and power were expressed relative to body weight to account for size differences between subjects.

The steps taken with respect to data reduction were as follows. The measures of peak torque $(\mathrm{N} . \mathrm{m} / \mathrm{kg})$, total work $(\mathrm{J} / \mathrm{kg})$ in the best work repetition (BWR) and average power, BWR (W/kg) were recorded and served as the basis for all subsequent ratio calculations which were: reciprocal ratios (elbow $\mathrm{F}$ to $\mathrm{E}$; knee $\mathrm{F}$ to $\mathrm{E}$ ) for torque, work, and power (see table 3); upper to lower extremity flexor ratios (U to L flexors); upper to lower extremity extensor ratios ( $\mathrm{U}$ to $\mathrm{L}$ extensors); $\mathrm{U}$ to $\mathrm{L}$ combined; or elbow $F+E$ over knee $F+E$ ratios for torque, work, and power (see table 4).

Two questions were addressed, the first relating to the raw data and the second to the

Table 3 Reciprocal (agonist to antagonist) ratios for work and power

\begin{tabular}{|c|c|c|c|c|}
\hline \multirow[b]{2}{*}{ Measure } & \multicolumn{2}{|c|}{ Elbow $F$ to $E$ ratio } & \multicolumn{2}{|c|}{ Knee $F$ to $E$ ratio } \\
\hline & $30^{\circ} / \mathrm{s}$ & $180^{\circ} / \mathrm{s}$ & $30^{\circ} / \mathrm{s}$ & $180^{\circ} / \mathrm{s}$ \\
\hline Peak torque $(\mathrm{N} . \mathrm{m} / \mathrm{kg})$ & $\begin{array}{l}1.01(0.16) \\
-\mathrm{NS}-\end{array}$ & $1.06(0.14)$ & $\begin{array}{l}0.57(0.09) \\
\mathrm{p}=0.0002\end{array}$ & $0.66(0.10)$ \\
\hline Best work repetition $(\mathrm{J} / \mathrm{kg})$ & $\begin{array}{l}1.06(0.15) \\
-\mathrm{NS}-\end{array}$ & $1.04(0.21)$ & $\begin{array}{l}0.65(0.13) \\
-\mathrm{NS}-\end{array}$ & $0.67(0.11)$ \\
\hline Mean power output $(\mathrm{W} / \mathrm{kg})$ & $\begin{array}{l}1.08(0.17) \\
-\mathrm{NS}-\end{array}$ & $1.08(0.23)$ & $\begin{array}{l}0.66(0.14) \\
-\mathrm{NS}-\end{array}$ & $0.65(0.12)$ \\
\hline
\end{tabular}

Results are mean (SD).

Significance level: $\mathrm{p}<0.05$.

$\mathrm{F}$, flexor; E, extensor. derived ratios. With respect to the raw data the following conditions were compared, use being made of one way analysis of variance (see table 2): flexion at 30 degrees/s; extension at 30 degrees/s; flexion at 180 degrees/s; extension at 180 degrees/s. With respect to the derived ratio data, the sole focus was on the effect of the test speeds on these ratios. Consequently Student's $t$ tests (related samples) were used to assess speed effects on the variables torque ratio, work ratio, and power ratio (see tables 3 and 4).

In this study the correlations of peak torque with total work varied widely, providing coefficients of determination $\left(r^{2}\right)$ of between 0.453 (elbow flexion at 30 degrees/s) and 0.777 (knee flexion at 180 degrees/s), thus leaving between 22 and $55 \%$ of the variance "unexplained". ${ }^{21}$ Several investigators have sought what are considered to be more functionally relevant measures than peak torque alone can provide. Some researchers, for instance, have placed emphasis on an "arc of maximum strength" (defined as the arc of motion during which maximum torque is maintained within $2 \mathrm{~N}$.m of the peak torque), on the grounds that this measure is more important functionally than a single point reading of the peak torque. ${ }^{22}$ Perrin $^{7}$ has cautioned that the return of peak torque in a rehabilitating muscle may not be closely related to that muscle's work and power capabilities, and that two curves of identical peak torque may reflect very different work and hence power outputs. From a clinical point of view, it may well be a muscle's full range output (work) or that output per unit time (power) that is more relevant than merely the tension that can be developed at the mechanically most favourable point in the range of motion. For this reason the primary focus of this study was on work and power ratios.

\section{Results}

RAW MEASURES

When expressed in units factored for body mass, there were no differences between flexors and extensors of the elbow at either of the test speeds, whether in terms of peak torque, total work, or average power output. However, in all these measures there were significant differences between flexors and extensors of the knee, the flexors being considerably weaker. Also, in all cases, elbow responses were significantly weaker 
Table 4 Upper to lower extremity (U/L) work and power output ratios at $30^{\circ} / \mathrm{s}$ and $180^{\circ} / \mathrm{s}$

\begin{tabular}{|c|c|c|c|c|c|c|}
\hline \multirow[b]{2}{*}{ Measure } & \multicolumn{2}{|c|}{$\begin{array}{l}\text { U/L: Flexors } \\
\text { (elbow F/knee F) }\end{array}$} & \multicolumn{2}{|c|}{$\begin{array}{l}\text { U/L: Extensors } \\
\text { (elbow E/knee E) }\end{array}$} & \multicolumn{2}{|c|}{$\begin{array}{l}\text { U/L: Combined } \\
(\text { elbow } F+E / k n e e ~ F+E)\end{array}$} \\
\hline & $30^{\circ} / \mathrm{s}$ & $180^{\circ} / \mathrm{s}$ & $30^{\circ} / \mathrm{s}$ & $180^{\circ} / \mathrm{s}$ & $30^{\circ} / \mathrm{s}$ & $180^{\circ} / \mathrm{s}$ \\
\hline Peak torque (N.m/kg) & $\begin{array}{l}0.48(0.09) \\
\mathrm{p}=0.0088\end{array}$ & $0.53(0.11)$ & $\begin{array}{l}0.27(0.06) \\
\mathrm{p}=0.0001\end{array}$ & $0.33(0.06)$ & $\begin{array}{l}0.35(0.06) \\
\mathrm{p}=0.0000\end{array}$ & $0.40(0.07)$ \\
\hline Best work repetition $(\mathrm{J} / \mathrm{kg})$ & $\begin{array}{l}0.72(0.15) \\
-\mathrm{NS}-\end{array}$ & $0.70(0.18)$ & $\begin{array}{l}0.44(0.09) \\
- \text { NS - }\end{array}$ & $0.45(0.09)$ & $\begin{array}{l}0.54(0.09) \\
- \text { NS - }\end{array}$ & $0.55(0.11)$ \\
\hline Mean power output (W/kg) & $\begin{array}{l}0.50(0.11) \\
-\mathrm{NS}-\end{array}$ & $0.53(0.12)$ & $\begin{array}{l}0.30(0.06) \\
- \text { NS - }\end{array}$ & $0.32(0.07)$ & $\begin{array}{l}0.38(0.06) \\
- \text { NS - }\end{array}$ & $0.39(0.06)$ \\
\hline
\end{tabular}

Results are mean (SD).

Significance level: $\mathrm{p}<0.05$

$\mathrm{F}$, flexor; E, extensor.

than knee responses. Table 2 gives the raw data and results of the one way analysis of variance and the post-hoc tests (Tukey method).

The speed related decrements in peak torque were larger for the lower extremity than the upper, and largest of all in the case of knee extensors. In the upper extremity the rates of decrement were similar in both flexors and extensors, so that $\mathrm{F}$ to $\mathrm{E}$ ratios remained constant when speeds of 30 and 180 degrees/s were compared (table 3 ).

DERIVED RATIOS

Reciprocal (agonist to antagonist) ratios

From the raw data, elbow $\mathrm{F}$ to $\mathrm{E}$ and knee $\mathrm{F}$ to $E$ ratios were calculated. The effects of a sixfold increase in speed, from 30 to 180 degrees/s, on torque, work, and power ratios were determined (table 3). In the case of the upper extremity all $\mathrm{F}$ to $\mathrm{E}$ ratios were unaffected by speed: essentially elbow flexors generated the same levels of torque, work, and power as elbow extensors, regardless of speed.

In the lower extremity, because extensor peak torques decreased significantly more rapidly than flexor peak torques as speed increased, there was a significant increase in knee $F$ to $E$ ratios for peak torque. In the range of speeds tested, however, this effect was confined to peak torque: knee $\mathrm{F}$ to $\mathrm{E}$ ratios for work and power were unaffected by speed.

In short, the increase in speed from 30 to 180 degrees/s had no effect on the elbow $\mathrm{F}$ to $\mathrm{E}$ ratio for torque, although there was a significant increase in the knee $\mathrm{F}$ to $\mathrm{E}$ ratio for torque, caused by the disproportionately large decrease in flexor peak torque at the higher speed.

Of prime concern here, however, was the fact that work output $\mathrm{F}$ to $\mathrm{E}$ ratios remained constant at around 1.05 for the elbow and 0.66 for the knee, regardless of speed and that power output $\mathrm{F}$ to $\mathrm{E}$ ratios similarly remained constant at 1.08 for the elbow and 0.66 for the knee. Clearly, in full range work production and power output at the speeds tested, normal elbow flexors are no different from elbow extensors, while knee flexors are capable of only about $66 \%$ of the work and power output of the knee extensors when tested in a seated position.

Upper to lower extremity ratios

Because lower extremity peak torques decreased at a faster rate than those of the upper extremity, there were significant speed related increases in flexor, extensor, and combined flexor plus extensor upper to lower extremity peak torque ratios (table 4). However, upper to lower extremity ratios for work and power showed no similar inclination to change as a result of the sixfold increase in speed from 30 to 180 degrees/s. In this regard flexors of the upper extremity produced $71 \%$ of the work and $52 \%$ of the power of those of the lower extremity, and extensors of the upper extremity produced $45 \%$ of the work and $31 \%$ of the power of those of the lower extremity, regardless of speed. Combined flexors and extensors of the upper extremity produced $55 \%$ of the work and $39 \%$ of the power of the lower extremity. The constancy of the upper to lower extremity ratios for work and power is attributable to the fact that elbow and knee work production levels fell at the same rate, while power generation levels increased at the same rate, between 30 and 180 degrees/s.

\section{Discussion}

Motor impairments, as a generalisation, are characterised by reductions in force generation, speed of motion, and segment ranges of motion. In a study of ambulatory patients with multiple sclerosis, ${ }^{23}$ it was found that half registered $0 \mathrm{~N} . \mathrm{m}$ at an isokinetic knee extension speed of 275 degrees/s. It would be spurious to assume, however, that limbs moving against gravity at almost 275 degrees/s were not generating substantial torques. This artifact of isokinetic technology, which records torques only when the preset machine speed is reached, requires that test speeds be well within the subject's capacity if meaningful torque, work, and power data are to be collected. In the present study, two test speeds in the lowest third of the range of testable speeds permitted by the Cybex 6000 were chosen because it is unlikely that, in the early stages of rehabilitation after musculoskeletal injury, subjects would be able to generate significant work and power outputs at speeds above 180 degrees/s. In functional restoration of sports persons, however, the goal of rehabilitation is a return, via normal function, to the higher levels of output required for competition. This requires eventual specific training for full range high speed musculoskeletal outputs commensurate with their sports. Fortunately, it has been shown that training at one speed produces a transfer effect to velocities both above and below the training speed. ${ }^{24}$

The findings of this study that elbow flexors are as strong as elbow extensors but knee flexors are not as strong as knee extensors echo established findings on strength of the elbow relative to the knee in healthy young adults. ${ }^{89}$ 
The central problem of this study, however, was to ascertain whether an increase in speed between 30 and 180 degrees/s elicits differential decrements of elbow and knee extensors and flexors to the extent of altering the upper to lower extremity strength ratios.

Although significant isokinetic responses may differentiate trained from untrained individuals, ${ }^{25}$ this study confirms recent findings ${ }^{26}$ that among competitively active athletes neither level of play nor nature of sport involvement exerted significant effects on any measures made, when differences due to body weight are factored out.

This study suggests that among intercollegiate level competitive athletes, regardless of the sport, speeds through the range of $30-180$ degrees/s have no effect on elbow $\mathrm{F}$ to $\mathrm{E}$ or knee $\mathrm{F}$ to $\mathrm{E}$ ratios and no effect on upper limb to lower limb ratios for work output or power production. Upper limb flexors are capable of over $70 \%$ of the work output of lower limb flexors, while upper limb extensors are capable of less than $45 \%$ of the work output of lower limb extensors. These findings have implications in the rehabilitation programmes of injured athletes who, in the early stages of restoration of function, may not be able to match the high movement speeds involved in their events, yet can be strengthened, and monitored, at lower speeds.

It is unlikely that the findings presented here can be of use in directing, for example, the exercise regimens of lower extremity disabled athletes confined to wheelchair events, as these athletes may effectively have lost lower extremity strength completely and permanently. The results are, however, expected to inform decisions about training/rehabilitation of adult male athletes who have bilateral lower (or upper) extremity injuries precluding use of the contralateral limb as an indicator for goal setting. It is customary in cases of unilateral limb injury, to use the unaffected limb as a guide to functional restoration. However, natural bilateral dominance ratios need to be considered. If both limbs are injured, the facility of contralateral comparison is lost. In such cases upper to lower extremity work and power ratios could be used. If for example, arm extensor work and power outputs (assumed on the basis of results of this study to be 45 and $31 \%$ respectively of the capacity of normal lower extremities) are measured, then target work and power goals for the bilaterally injured knee extensors can be set. Similarly, knowledge of upper to lower extremity ratios can inform training goals in the rehabilitation of bilaterally injured upper extremity cases. The suggestion of this paper is that, in cases of bilateral upper extremity injury, a useful guide to rehabilitation could be to target combined flexor plus extensor upper extremity work capacity goals at $55 \%$, and power output goals at $39 \%$ of the measured capability of the unaffected lower extremity.

1 Fenn WO, Marsh BS. Muscular force at different speeds of shortening. F Physiol (Lond) 1935;85:277-97.

2 Hill AV. The heat of shortening and the dynamic constants of muscle. Proc R Soc Lond B Biol Sci 1938;26:136-95.

3 Caiozzo VJ, Perrine JJ, Edgerton VR. Training induced alterations of the in-vivo force-velocity relationship of human muscle. $\mathcal{F} \mathrm{Appl} \mathrm{Physiol} \mathrm{1981;51:750-4.}$

4 Charteris J, Goslin BR. The effect of position and movement velocity on isokinetic force output at the knee. $\mathcal{F}$ Sport Med Phys Fitness 1982;22:154-60.
Sport

5 Wickiewicz TL, Roy RR, Powell PL, et al. Muscle architecture and force-velocity relationships in humans. 7 Appl ture and force-velocity

6 Hortobagyi T, Katch FI. Eccentric and concentric torquevelocity relationships during arm flexion and extension. Eur f Appl Physiol 1990;60:395-401.

7 Perrin DH. Isokinetic exercise and assessment. Champaign: Human Kinetics Publishers, 1993.

8 Goslin BR, Charteris J. The human elbow and knee: functional relationships and phylogenetic considerations. Hum Biol 1982;54:491-500.

9 Falkel JE, Sawka MN, Levine L, et al. Upper to lower body muscular strength and endurance ratios for women and men. Ergonomics 1985;28:1661-70.

10 Sawka MN. Physiology of upper body exercise. Exerc Sport Sci Rev 1986;14:175-211.

11 Ghena DR, Kurth AL, Thomas M, et al. Torque characteristics of the quadriceps and hamstring muscles during conistics of the quadriceps and hamstring muscles during con1991;14:149-54.

12 Charteris J, Goslin BR. Torque, work and power capabilities of the elbow in normal young adults: clinical implications and applications. South African fournal for Research in Sport, Physical Education and Recreation 1986;9:39-49.

13 Perrine JJ, Edgerton VR. Muscle force-velocity and power velocity relationships under isokinetic loading. Med Sci Sport 1978;10:159-66.

14 Berg K, Blanke D, Miller M. Muscular fitness profile of female college basketball players. F Orthop Sport Phys Ther 1982;7:59-64

15 Baltzopoulos V, Brodie DA. Isokinetic dynamometry: applications and limitations. Sport Med 1989;8:101-16.

16 Morris A, Lussier L, Bell G, et al. Hamstring/quadricep strength ratios in collegiate middle distance and distance runners. Physician and Sports Medicine 1983;11:71-7.

17 Davies GJ. A compendium of isokinetics in clinical usage and rehabilitation techniques. 4 th ed. Onalaska: S and S Publishers, 1992 .

18 Thorstensson A, Karlsson J. Fatiguability and fibre composition of human skeletal muscle. Acta Physiol Scand 1976;98:318-22.

19 Pappas AM, Zawacki RM, Sullivan TJ. Biomechanics of baseball pitching: a preliminary report. Am $\mathcal{F}$ Sports Med 1985;13:216-22.

20 Charteris J, Scott PA. Morphology-related isometric trunk strength of South African manual workers: implications for the prevention of occupational low-back stress. International fournal of Occupational and Safety Ergonomics 1996;2:336-46.

21 Silverstein AB. Graphing correlation coefficients: II. An alternative procedure. Percept Mot Skills 1988;67:861-2.

22 Reid DC, Oedekoven G, Kramer JF, et al. Isokinetic muscle strength parameters for shoulder movements. Clinical Biomechanics 1989;4:97-104.

23 Armstrong EL, Winant MD, Swasey RP, et al. Using isokinetic dynamometry to test ambulatory patients with isokinetic dynamometry to test ambulatory
multiple sclerosis. Phys Ther 1983;3:1274-9.

24 Coyle E, Feiring D, Rotkins T, et al. Specificity of power mprovements through slow and fast isokinetic training. $\mathcal{F}$ Appl Physiol 1981;51:1437-42.

25 Öberg B, Moller M, Gillquist J, et al. Isokinetic torque levels for knee extensors and knee flexors in soccer players. Int $\mathcal{F}$ Sports Med 1986;7:50-3.

26 Zakas A, Mandroukas K, Vamvakoudis E, et al. Peak torque of quadriceps and hamstring muscles in basketball and soccer players of different divisions. 7 Sports Med Phys Fitness 1995;35:199-205.

\section{Take home message}

At slow to moderate isokinetic speeds, upper and lower limb flexor to extensor work and power output ratios are constant at 1.05 and 0.66 respectively, while upper to lower limb flexors and upper to lower limb extensors have work output ratios of about 0.70 and 0.45 and power output ratios of about 0.52 and 0.31 respectively. These findings could be useful in establishing rehabilitation goals after bilateral upper or lower limb musculoskeletal injury. 